\author{
Entrevista
}

\title{
O rompimento da barragem de Fundão, da mineradora Samarco, em Mariana-MG (5/11/2015): vozes de atingidos por um crime ambiental em curso
}

\author{
Aparecida Maria Gonçalves (Cida)
}

Assistente Social, técnica da equipe CONVIVER, dispositivo referência na oferta de saúde mental e atenção psicossocial no território, aos atingidos pelo rompimento da barragem de Fundão, em Mariana-MG (Secretaria Municipal de saúde de Mariana). Discente do curso de Especialização "Serviço Social, Políticas Sociais e Processos de Supervisão de Estágio", Faculdade de Serviço Social-UFJF.

Considerado o maior crime ambiental do Brasil, com mais de $600 \mathrm{~km}$ de extensão atingidos pelos rejeitos da lama, a barragem de Fundão rompeu-se no dia 5 de Novembro de 2015, e depois de semanas em curso, essa lama atravessa Minas Gerais e chega ao estado do Espírito Santo. Caracteriza-se como um crime ambiental em curso, não só pelo percurso que a lama fez, mas pelos impactos negativos que ela continua causando na vida das pessoas e no meio ambiente. Passado mais de três anos ocorre outro crime ambiental de grandes proporções, também em Minas Gerais, no município de Brumadinho, e o que se tem de mais concreto sobre a mineração no Brasil é a iminência de ruptura de outras barragens. Esta realidade interpela e diz respeito, não só as comunidades atingidas ou em iminência de serem atingidas, mas a sociedade como um todo, diante deste modelo de mineração, tão devastador da natureza e de tantas vidas.

Esta entrevista traz as vozes de duas pessoas atingidas pelo crime ambiental de Mariana/MG, moradores da localidade rural de Bento Rodrigues, que sofreram o deslocamento forçado para a zona urbana da cidade de Mariana. Os depoimentos de Marly e Francisco, antigos moradores de Bento Rodrigues, revelam alguns dos impactos e as alterações no modo de vida, sofridos por eles e por toda comunidade atingida por este crime ambiental, mas também demonstra o processo contínuo de organização, resistência e luta por direitos e por justiça.

1-Cida: Primeiro, Marly e Francisco, eu quero agradecer em nome da Revista Libertas, de toda a equipe, por vocês terem aceitado fazer essa entrevista. E dizer da importância dessa entrevista, que é um momento para vocês terem mais um espaço de fala, de vocês terem voz para dizer um pouco pra gente como que tem sido o cotidiano de vocês, a partir do dia 5 de novembro de 2015, que foi o rompimento da barragem da Samarco, que também é conhecida como a barragem de Fundão. A gente sabe, que vocês vieram para Mariana, assim como outras pessoas das comunidades atingidas, 
em decorrência do rompimento da barragem, através de um deslocamento forçado, e que traz alterações na vida de vocês. Queria que vocês falassem sobre essas alterações, como era antes e depois da vinda para a zona urbana de Mariana, há mais de 3 anos. O que vocês têm percebido?

Francisco: É que lá em Bento Rodrigues, onde eu passei a minha infância, a gente tem a lembrança do que a gente viveu lá, dos colegas, do pessoal que a gente tinha amizade, a gente brincava de bola, ia estudar. Então a vida lá era melhor do que na cidade, porque lá a gente podia plantar, a gente colhia o que a gente plantava, e a horta que a gente plantava era mais saudável do que comprar na cidade que a gente não sabe o que usou, se é orgânico ou se usou algum agrotóxico, então na roça é mais saudável. E aqui na cidade é muito diferente, o costume é outro, tem que vigiar mais a criança ir na escola, porque lá da casa da gente dava pra acompanhar a criança ir e voltar da escola, por exemplo, como fazia com a minha filha mais velha. E aqui é diferente a gente tem que ficar vigiando mais, tem que levar em ponto pra pegar ônibus para ir pra aula.

Marly: Tem que esperar voltar da escola também. E tinha uma coisa muito gostosa que era a convivência com os vizinhos, como se diz, a gente ter um bom vizinho é melhor do que parente, porque às vezes um parente não faz tanto pela gente como um vizinho faz. Eu sinto muito a falta da convivência com os vizinhos, eu estudava em Santa Rita Durão e deixava a Ana Flávia com a minha vizinha. Tinha essa confiança em deixar, eu podia vir pra Mariana e deixar com ela, para qualquer lugar que eu fosse, que não desse pra eu levar, ela ficava de boa vontade, nunca foi problema deixar filho com ninguém lá em Bento e aqui a gente já não tem esse costume com ninguém então fica até difícil pra gente sair, às vezes a gente precisa sair e não tem com quem deixar, então eu sinto muito a falta da convivência com os vizinhos. E depois do rompimento, nesse deslocamento isso mudou, as pessoas estão diferentes, as pessoas da comunidade estão diferentes, eu não sei se é porque cada um mora em um bairro e quase não se vê então tá se tornando uma coisa estranha, parece que a gente não é do mesmo lugar mais. Então depois do rompimento isso foi prejudicado, eu ainda tenho contato com os vizinhos da minha rua mas de outras ruas já está distante. Fico pensando como vai ser a minha volta porque, uma pessoa que faz falta e vai fazer falta pra mim no novo Bento, que eu fico imaginando como vai ser a minha vida quando eu estiver lá, é a minha mãe, ela ia na minha casa todo dia, eu fico pensando "Meu Deus como vai ser quando eu estiver lá, a minha mãe não vai na minha casa mais", então eu fico pensando que não vai ser a mesma coisa. Então, o que eu acho que vai ser bom de voltar é que vai ser um lugar longe de fumaça, essas coisas de cidade, vai ter um pouco mais de liberdade, porque depois que a gente tá aqui não pode deixar mais portão aberto, tem que estar trancando porta de casa e lá não, lá a gente dormia com o portão aberto. A gente só trancava se fosse viajar e ficar fora 1 semana, porque tinha essa convivência com os vizinhos: "ah eu vou sair você toma conta". Então aqui você tem que deixar 24 horas fechado e isso me aborrece muito, porque a gente tinha a liberdade de deixar tudo aberto, as crianças podiam brincar na rua, aqui não pode, se for pra rua a gente tem que estar ali pra vigiar por segurança, porque lá não tinha esse movimento de carro aqui já tem, muda tudo, é totalmente diferente a vida da gente antes e agora. 
2-Cida: Quais os principais impactos que vocês consideram que o rompimento da barragem causou na vida de vocês, na vida dos seus filhos e na comunidade? Vocês consideram que as ações desenvolvidas pela empresa e pelo poder público junto com vocês da comunidade, têm dado algum resultado diante desses impactos?

Francisco: Eu acho que o impacto pra gente, que é nascido e criado na zona rural, e vir forçado pra cidade assim sem planejamento de nada. Então acho que o impacto é o costume, se adaptar com o costume da cidade que são outros costumes. E as crianças também estranharam, como o local diferente de escola. No início teve muito problema na primeira escola que eles foram estudar, ai com muita luta, teve várias reuniões na escola, pra poder tentar mudar o lugar. E a empresa arrumou um outro lugar adaptado com o nome que tinha na antiga Escola Municipal de Bento Rodrigues, ai já melhorou pras crianças, já deu uma melhora boa depois que mudaram de escola.

Marly: Ah, acho que é a falta de paz e sossego. Acho que o maior impacto que tem na minha vida é esse, porque de lá pra cá acabou, a gente não tem paz, não tem sossego, eu pelo menos posso falar por mim, eu já não sinto paz, não sinto sossego, o que a gente tinha lá perdeu. Em relação também às crianças, de estudarem, teve muito problema. Até fiquei muito triste de saber em reunião, eu ouvi que estava tendo abaixo assinado para que as crianças não estudassem na escola. Isso me doeu muito, sem contar que as crianças também estavam sofrendo preconceito na escola. Como a gente adulto sofre na rua, as crianças estavam sofrendo na escola. As crianças saiam pra brincar no recreio e voltavam chorando. Eu ouvi da professora, não foi ninguém que contou, que não estava aguentando ver as crianças sofrerem, e isso estava doendo nela também, que como eu era mãe, que juntasse as mães pra ver se resolvia aquele problema, porque não estava dando mais. Então do mesmo jeito que a gente estava sofrendo preconceito, as crianças também estavam sofrendo na escola, aquelas brincadeiras de que as crianças vieram da lama, o que elas estavam fazendo ali, que a roupa era de doação, então eram várias piadinhas assim que incomodavam as crianças. Depois do rompimento de Brumadinho parece que voltou tudo de novo, tinha dado uma pausa, a gente não estava ouvindo mais nada desses preconceitos, dessas piadinhas, mas assim que rompeu a de Brumadinho começou tudo de novo. A gente já sai na rua e começam a falar de nós de Bento Rodrigues, que a gente devia ter morrido mesmo, porque se nós estamos nessa situação é porque nós quisemos, que a empresa chegou a falar pra nós de Bento Rodrigues que era pra nós sairmos, que a gente não saiu porque não quis. A gente da comunidade sabe que isso não é verdade, que ninguém chegou pra falar que a represa a qualquer momento ia romper. A gente sabia que tinha represa lá, portanto quando tinha reunião lá a gente ia e perguntava se aquilo um dia podia acontecer. Empregados da empresa Samarco falavam que isso nunca ia acontecer porque tinha pessoa pra monitorar 24 horas, que a gente podia ficar tranquilo que isso não ia acontecer, e um dia aconteceu... Então a gente sofre com isso, escuta as pessoas falando que devia todo mundo ter morrido, que a gente se aproveita da empresa, que está extorquindo a empresa, tá se aproveitando. Só que as pessoas que falam isso não vê a dor que é estar no nosso lugar. Muita gente escutando isso já falou: "você quer trocar então? Me dá sua casa e fica sem casa pra ver se você vai gostar". A pessoa nem falou nada. Jogar pedra no outro é fácil, agora estar no lugar ninguém quer. 
3-Cida: A gente sabe que após o rompimento da barragem houve um processo de organização das comunidades. Como que se deu esse processo de organização das comunidades rurais atingidas, para reivindicar os direitos e resistir, após o rompimento da barragem?

Francisco: Através de reuniões começou a decidir, mas no início a gente fazia reunião mas vinham poucas pessoas, e aí era uma luta, porque quanto mais pessoas, melhor para combater e debater com a empresa as questões que eram levantadas para resolver. Mas foi passando o tempo, fazia reuniões, não tinha decisão de nada, a gente voltava pra casa sem saber porque não tinha resolvido. Chegou um momento que a comunidade percebeu que tava passando tempo e não tava resolvendo nada. Aí as pessoas começaram a ir nas reuniões, começaram os processos de documentação, escolha de terreno, aprovação nossa e votação do terreno. A comunidade reuniu e escolheu a (localidade) lavoura. Foi um longo processo pra resolver a documentação da prefeitura, voltar pra (fundação) Renova, pra gente ir conseguindo os direitos. Demorou muito. Agora, de mais ou menos um ano pra cá, que começou a andar as coisas, começou a engatinhar. E agora esse ano já tem a proposta de começar a construção das casas, e alivia mais pra gente, de ver que teve muita luta ainda tem muita, mas a gente já vê que tá caminhando.

Marly: E é bom a gente lembrar, que tudo que a gente tem conquistado até hoje a gente tem que agradecer a Deus, em primeiro lugar, ao promotor doutor Guilherme, à comissão com pessoas da comunidade, que tem mais disponibilidade de tá acompanhando de perto as reuniões da empresa. Tem que lembrar também do Movimento dos Atingidos por Barragens - MAB, que são pessoas que tem mais experiência, com movimento e essas coisas, e passam isso pra gente. E também a gente conquistou, através da luta, uma assessoria técnica da Cáritas Brasileira, pra nos orientar e ajudar a gente a cobrar os nossos direitos. Então não é só nós e a empresa, tem esse grupo que tá nos ajudando a conquistar os nossos direitos, porque se fosse só por nós a gente não sabia como fazer e onde deveria recorrer. A gente não sabia como é ser atingido, hoje a gente tá aprendendo é com a luta. Não é fácil, mas graças a Deus, e através de pessoas boas, a gente tá conquistando aos poucos os nossos direitos.

4--Cida: Depois de mais de três anos e meio de luta e reivindicação por direitos, de descobrir como é ser atingido, vocês consideram que ainda estão em situação emergencial ou não? como vocês enxergam a situação de vocês hoje em Mariana, por conta desse deslocamento forçado?

Marly: Eu considero emergencial, porque a gente ainda não tá no que é da gente. A gente tá um tempo em casa alugada pela empresa, então a gente está ainda em situação emergencial. Até porque uma coisa que a gente sempre pediu em reuniões, para eles pelo menos ter o bom senso de pedir desculpas pelo que aconteceu, que isso é culpa deles e não é do atingindo. A gente escuta aí, por bocas de segundos, que a gente é culpado pelo que aconteceu, mas as pessoas não vê a gente como vítima. A gente sempre pediu pra eles pedir desculpas pra gente, pelo menos pra amenizar. Isso eles nunca fizeram. Ontem fez seis meses do rompimento de Brumadinho e eles colocaram uma nota pedindo desculpas, a Vale pedindo desculpas para o pessoal de Brumadinho. É isso que a gente queria, que a Samarco tivesse bom senso de pedir desculpas, pela simples palavra, nas redes de canais de televisão e eles não fizeram isso. Deixam as pessoas humilhar a gente e eles não ve que quem é culpado é eles, que construiu a barragem lá por cima da gente. Não foi nós que construiu a casa em cima de barragem e que deixou romper, foi eles também. Nenhum atingido foi lá cutucar a barragem pra romper não. Então a gente queria que eles pedissem pelo menos desculpas, já que ninguém foi preso pelo crime. 
Francisco: Eu considero também, porque depois de tantas lutas e conquistas que a gente teve, a gente ainda não conseguiu ter nossa casa pronta, tem o processo de indenizações, que iniciou mas não finalizou, então tem muita coisa para ser resolvida ainda. A gente espera que eles tentem fazer esse processo andar mais rápido, porque muitas pessoas de idade pensam que não vão conseguir ver a casa deles pronta. Então a gente ainda não terminou, a luta ainda continua.

Marly: Mesmo porque pra receber a indenização a gente teve que passar por um cadastro e mesmo assim, graças a assessoria da Cáritas, que viu que o cadastro que eles queriam aplicar na gente era fora do comum, eles queriam um cadastro que valia pra bacia inteira, daqui até la no Espírito Santo, onde foi a lama. Então o pessoal viu que não tava certo, que era pra separar as coisas. $\mathrm{O}$ que aconteceu em Bento, nos distritos aqui de Mariana, tem que ser um cadastro diferenciado do que foi pra lá, porque aqui a gente perdia muito mais. Aí graças a Caritas, junto com o promotor, que refez junto com a empresa o cadastro pra aplicar pra gente.

\section{5-Cida: E vocês fizeram parte da construção desse novo cadastro?}

Marly: Sim. E isso que é importante. No cadastro que eles fizeram não tinham participação do atingido e nesse que foi reformulado, já teve a participação do atingido. E foi isso que a Caritas bateu, que não tinha a participação das vítimas no cadastro, por isso ele não valia. Tinham palavras que a gente não sabia o que significava, então tava tirando os direitos mesmo. Perguntava sobre a casa da gente tinha, com umas palavras lá, que se a gente não soubesse responder a gente tava colocando a casa da gente como um barraco. Então a gente não tinha esse conhecimento. A gente nunca precisou passar por isso, a gente não sabia coisas técnicas sobre rompimento de barragem, a gente não tem esses estudos para entender essas coisas técnicas. Então a Caritas veio para explicar as coisas pra gente, numa linguagem que a gente entende.

6-Cida: Marly, você traz uma questão muito importante, quando você diz dessa participação de vocês na construção do cadastro. Como os moradores das comunidades atingidas participam dos processos de decisão, das ações propostas junto aos representantes do poder público e da empresa Samarco? E dentro desse processo de decisão, vocês tem voz?

Marly: Nem sempre, porque como eu já disse, a empresa faz de tudo para tirar os direitos. Então tem coisas que eles fazem lá que quando chega pra gente já tá praticamente pronto. Se não tivesse assessoria para orientar, a gente abre mão de direitos sem saber que tá abrindo mão. A gente é até orientado para a gente não ficar assinando documentos da empresa, se a gente tiver dúvidas. Primeiro é para procurar a assessoria para orientar. Eu mesma já passei por isso, chegou um papel pra assinar e eu falei: "não vou assinar, a gente é orientado em reuniões que se a gente tem dúvida a gente não assina porque eu posso tá perdendo a minha casa." Então se tiver dúvida é para não assinar, eu mesmo falo pra não assinar, primeiro procura quem entende.

7-Cida: A demanda de vocês tem sido acolhidas? Quando vocês estão nessas reuniões, quando vocês apresentam uma demanda, alguma necessidade que é de vocês, da comunidade, eles acolhem essas demandas? 
Francisco: Em muitas reuniões passadas, as vezes a comunidade levava essas demandas e eles não davam respostas, eles levavam e pediam tempo pra eles analisar. Quando eles voltavam muitas coisas não estavam de acordo. Então muita questão foi resolvida através de juiz, só através de juiz que eles davam uma resposta que os atingidos precisavam. Se não fosse em audiência pública não resolvia, aí o promotor passou a levar as questão que eles não resolviam lá pra juíza, então a juíza decidia, e eles passaram a concordar com as proposta dos atingidos.

8-Cida: Vocês consideram que agora vocês tem voz nas reuniões, vocês têm espaço pra falar, pra reivindicar?

Francisco: Sim, o Ministério Público deu esse poder de voz para os atingidos.

Marly: E até hoje as demandas estão sendo tratadas em juiz. Portanto, tá tendo audiência agora uma vez por mês, porque não tá adiantando mais ter reuniões. A gente vai lá pra ter respostas e eles não dão respostas. Então achou-se melhor ter a presença da juíza, por isso que agora todo mês tem uma audiência. Aí tudo que os atingidos reivindicam levam pra juíza, pra ser divulgado lá com a participação dos atingidos.

9-Cida.Entre as lutas pelos direitos dos atingidos, o que vem sendo feito pelos representantes do Poder Público e da Empresa Samarco-Fundação Renova, para preservar os costumes, a história, a memória das comunidades rurais atingidas?

Marly: Pelo que eu vejo eles não tem feito quase nada não. De vez em quando eles levam os idosos pra passear, mas tirando isso, eu não tô vendo nada não.

10-Cida: $E$ o que vocês tem feito, enquanto comunidade, pra preservar os costumes e as tradições lá de Bento Rodrigues?

Francisco: As tradições são feitas sim. As festas religiosas tão seguindo aí, faz dois dias na igreja aqui. O padre celebra pra gente lá no Bento antigo, na Igreja de Nossa Senhora das Mercês. Fizeram uma cobertura onde era o local da Igreja do São Bento, e tem uns momentos festivos religiosos. Então o pessoal faz lá tudo pra não perder o costume, a tradição do lugar. É a festa de São Bento, que é em julho, dia de Nossa Senhora, em setembro, e tem a de Nossa Senhora Aparecida, em Outubro.

11-Cida.As comunidades rurais atingidas, foram construídas ao longo dos séculos, tem histórias, tradições, gerações de famílias que já residiam a vários anos. Vocês sabiam ou foram informados sobre a existência e os riscos da barragem de Fundão? Vocês foram treinados para caso acontecesse o rompimento? 


\section{Marli e Francisco: Não!}

Francisco: A gente não teve treinamento nenhum. A gente sabia que a barragem era perigosa, sempre nas reuniões que eles faziam em Bento Rodrigues com a comunidade, perguntava sobre a barragem e eles diziam que estava tudo bem, que não tinha perigo nenhum, que tinha segurança. Então no dia em que rompeu a barragem ninguém foi avisado de nenhum perigo. A gente sobreviveu por Deus. A gente está vivo aqui hoje graças a Deus, mas, por eles a gente não teve alerta de nada.

Marli: Antes eles não falavam que tinha perigo, agora depois do rompimento a gente não pode entrar porque é área de risco. Instalaram sirene, que tinha que ter antes, agora é fácil. Vira piada, o que tinha que ter sido feito antes a empresa vem fazer agora para mostrar que faz bonito. Um monte de sirene para assustar os outros, eles tinham que ter tomadas estas providências antes de acontecer, igual no dia de treinamento, eles ensinaram quase que o mesmo percurso do dia em que aconteceu. Eles ensinaram para os atingidos o mesmo percurso que a gente tinha feito. Então a gente que ensinou a eles como correr, porque até então eles não sabiam. E aí vira piada. A gente que se salvou, ninguém ensinou nada. A gente viu e teve que correr mesmo, sem saber pra onde. Deus é que sabe como a gente correu.

\section{2-Cida.O que significa para vocês, da comunidade rural de Bento Rodrigues, a construção da nova comunidade, no lugar escolhido pelas famílias para o reassentamento? E o que vocês esperam das novas comunidades?}

Francisco: Eu espero que depois que a gente veio forçado para cidade, então, a gente adaptou a um outro costume que não era nosso, então, a gente já começou a adaptar na cidade, dentro destes três anos e meio que a gente está aqui. E agora, depois que a gente for para o novo reassentamento, vai ser um outro costume, vai ter o mesmo nome, comunidade Bento Rodrigues, mas não é o mesmo antigo, vai ser um outro costume, outra adaptação. A gente vai ter que acostumar, a gente vai ter outros vizinhos, uma nova comunidade, a gente vai ter que adaptar ao costume que a gente tinha lá de novo, a gente vai tentar isto. Muitas famílias já não quiseram ir para lá, vão ficar na cidade. Espero que todo mundo que chegue lá se adapte e não queiram voltar para cidade. Este lugar nosso é um lugar diferente, um lugar desconhecido que a gente nunca viveu lá, vai ter que acostumar viver lá de novo. E a história da gente ficou lá no Bento antigo, agora é uma nova história. É o recomeço de uma nova história, a gente vai viver um logo período de adaptação. O que eu sempre falo para as outras pessoas, desde o rompimento da barragem até a gente voltar para o reassentamento, e começar pegar um novo costume, vai viver um processo de mudança de costumes, por um período de 10 anos ou mais.

Marli: Tenho esperança que a gente volte logo, mas também, eu peço a Deus que reine a paz lá, antes de tudo, porque do rompimento até hoje eu me sinto assim, sem paz. O que a gente tinha lá acabou, nosso sossego, nossa liberdade. Eu peço a paz, que Deus abençoe nossa comunidade, que o crime não aconteça mais, porque o crime aconteceu no dia 05 de novembro, e com esta Fundação Renova, ele se renova todo dia. Ser atingida ensina a gente a aprender muitas coisas, coisas que a 
gente nem sabia, a gente agora sabe. Só lutando que a gente vai conquistar. São os nossos direitos, os direitos não são dados. Os direitos são conquistados.

\section{3-Cida Marli e Francisco vocês trouxeram muitas coisas importantes nessa conversa, nesse diálogo nosso. E tem mais alguma coisa que vocês queriam acrescentar?}

Marli: O que eu quero acrescentar é só agradecer a Deus, por minha vida, pela vida da minha família, pelas pessoas que Deus colocou na minha vida, pessoas boas como você. E as pessoas da terapia que eu faço toda terça-feira, a Camila, o Eduardo (Grupo Bem Leve, do CONVIVER) e outras pessoas mais que já passaram. Nunca imaginava que um dia ia passar por psicólogos, coisas que eu não imaginava que ia passar.E pelas pessoas que estão nesta luta com a agente, que Deus nos dê força para a gente vencer todas as batalhas, porque a gente só está no começo. A briga é árdua, como diz o Dr. Guilherme, que Deus nos dê forças para a gente continuar lutando pelos nossos objetivos.

Francisco: Eu também quero agradecer primeiro a Deus, por a gente estar aqui vivo, com saúde, poder contar um pouco do que a gente passou lá e agradecer também ao Dr. Guilherme, que foi um anjo enviado por Deus, que está com a gente até hoje desde o início. Os outros órgãos, que também nos acompanham, o Ministério Público. Tem o MAB e a Cáritas brasileira, pela assessoria técnica. A comissão sempre acompanhou na luta e também pelas amizades que a gente fez no bairro, que a gente passou e morou, a gente fez bastante amizade. E espero que as coisas caminhem nos seus devidos lugares, direitinho e agradecer também por você dar esta oportunidade de falar alguma coisa, fazendo o seu trabalho. Sempre acompanhou a gente desde o início para nos dar força. Não deixa a gente desanimar. Então é com muita luta que a gente está aí firme e forte. A gente desanima mas volta. E eu vi um vídeo outro dia e postaram num grupo aí, que que fala que sempre quando a gente tem um problema na vida... a vida é como uma corda tem princípio, meio e fim. Às vezes, com um problema a gente pensa que já está no fim. A gente chega no fim da corda ela dá um nó e a gente fica amarrado, a gente não sabe para onde vai, o que vai acontecer, mas a gente tem que ter FÉ em Deus. E a gente tem o poder de recomeçar, a gente pode voltar no meio, e se a gente está no meio da corda é porque o fim ainda está longe. Eu acho que a gente ainda tem muita caminhada, mas o fim ainda não chegou e a gente está firme e forte. Dá um abraço na sua professora, porque incentivou você fazer este trabalho, a entrevista.

\section{Cida:}

Eu tenho que agradecer vocês, enquanto profissional, como pesquisadora em nome da Revista Libertas, por ter me recebido na casa de vocês, neste espaço tão particular, e poder compartilhar com outras pessoas, as histórias de luta por reconhecimento de direitos, o cotidiano de como ser atingido, e este reinventar de modos de vida de vocês e da comunidade. Muito obrigada! Agradeço também, a minha professora, Mônica Grossi, da Faculdade de Serviço Social da UFJF. 